\title{
Suporte social na reabilitação da mulher mastectomizada: o papel do parceiro sexual
}

\author{
SOCIAL SUPPORT IN THE REHABILITATION OF MASTECTOMIZED WOMEN: \\ THE ROLE OF THE SEXUAL PARTNER \\ SOPORTE SOCIAL EN LAREHABILITACIÓN DE LAMUJER MASTECTOMIZADA: \\ EL ROL DEL COMPAÑERO SEXUAL
}

Raquel Gabrielli Biffi ${ }^{1}$, Marli Villela Mamede $^{2}$

1 Professora Doutora do Departamento de Enfermagem do Centro Universitário Barão de Mauá de Ribeirão Preto. rgbifi@hotmail.com

2 Professora Titular do Departamento Materno Infantil em Saúde Pública da Escola de Enfermagem de Ribeirão Preto/USP. mavima@eerp.usp.br

\author{
RESUMO \\ O estudo identificou os tipos \\ de suporte social oferecido \\ pelo parceiro sexual da \\ mulher com câncer de mama e \\ verificou como este apoio é \\ percebido por eles. \\ Participaram do estudo nove \\ parceiros de mulheres nessa \\ condição. Os dados foram \\ coletados por meio de \\ entrevistas e submetidos à \\ análise de conteúdo. Os \\ parceiros se perceberam \\ como importantes elementos \\ de suporte social para as suas \\ esposas oferecendo afeto, \\ estímulo ao auto cuidado e \\ auxilio nos afazeres \\ domésticos. Revelaram \\ dificuldades enfrentadas ao \\ oferecer suporte social as \\ quais estavam relacionadas à \\ esfera sexual, aos canais de \\ comunicação, à sensação de \\ impotência e insegurança \\ para lidar com as \\ implicações do diagnóstico e \\ reorganizar as atividades \\ domésticas.
}

\section{PALAVRAS-CHAVE}

Neoplasias mamárias. Reabilitação.

Saúde da mulher.

\begin{abstract}
This study identified the types of social support offered by the sexual partners of women with breast cancer and their perceptions about this support. Nine partners of women in this condition participated in the study. Data was collected through interviews and submitted to content analysis. Partners perceived themselves as important elements of social support to their wives, offering affection, stimulus to self-care and help with household chores. Difficulties faced in offering social support involved sexual relations, communication channels, the feeling of impotence and insecurity to deal with the implications of the diagnosis and to reorganize household chores.
\end{abstract}

\section{KEYWORDS}

Breast Neoplasms.

Rehabilitation.

Woman's health.

\section{RESUMEN}

El estudo identificó los tipos de soporte social ofrecido por el compañero sexual de la mujer con cáncer de mama y verificó cómo este apoyo es percibido por ellos. Participaron del estudio nueve compañeros de mujeres en esa condición. Los datos fueron recolectados por medio de entrevistas y sometidos a análisis de contenido. Los compañeros se percibieron como importantes elementos de soporte social para sus esposas ofreciendo afecto, estímulo al auto cuidado y auxilio en los quehaceres domésticos. Revelaron dificultades enfrentadas al ofrecer soporte social las cuales estaban relacionadas a la esfera sexual, a los canales de comunicación, a la sensación de impotencia e inseguridad para lidiar con las implicancias del diagnóstico y reorganizar las actividades domésticas.

\section{PALAVRAS CLAVE}

Neoplasmas de la mama. Rehabilitación. Salud de la mujer.

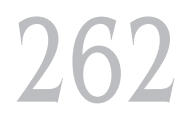




\section{INTRODUÇÃO}

Ao convivermos com mulheres portadoras de câncer de mama, submetidas a algum tipo de cirurgia e em processo de reabilitação, temos percebido que a história de vida, a condição física, emocional e familiar de cada uma pode interferir no enfrentamento do câncer.

Refletindo sobre as diversas necessidades que as mulheres com câncer de mama têm, desde problemas com a cirurgia e tratamentos a que são submetidas, percebemos necessidades e dificuldades que elas enfrentam quando retornam ao convívio do lar após a alta hospitalar.

Os relatos e queixas expressados por mulheres que vivenciaram o problema estão relacionados principalmente às suas dificuldades de interação com seus familiares. No entanto sabemos que uma relação familiar saudável poderá ajudá-las significativamente nessa nova condição de vida, criando um ambiente favorável para que possam enfrentar o câncer de forma menos sofrida.

Dependendo da fase de atendimento que a mulher se encontra, ou seja, na fase diagnóstica, cirúrgica ou em processo de reabilitação, as redes de suporte são distintas $^{(1)}$. O parceiro sexual, na fase de reabilitação, é uma das fontes mais importantes na assistência à mulher com câncer de mama.

Entendemos que o suporte social é formado por meio de laços sociais que se estabelecem entre os indivíduos no convívio social. As pessoas ligadas ou unidas por laços de afeto, consideração, confiança, entre outros, podem influenciar mudanças no comportamento e na percepção dos participantes, os quais poderão formar ou indicar a função da rede social.

O suporte social é considerado um fenômeno inter-pessoal expressado por intermédio de cuidados, da reafirmação de confiança e do mérito pessoal do indivíduo. É baseado nos laços sociais que se estabelece, entre as pessoas, na interação social. Se houver uma relação de reciprocidade em informações e ajuda pode-se assim, favorecer recursos psicológicos e físicos a uma pessoa, tornandoa capaz para, com sucesso, enfrentar as dificuldades encontradas ${ }^{(2)}$.
O suporte social se expressa de distintas formas e é evidente quando ${ }^{(3)}$ :

- envolve expressão de afeto positivo, tendo o poder de neutralizar a sensação de isolamento emocional ou solidão;

- envolve expressão de concordância, interpretação e/ou estimulação dos sentimentos da pessoa apoiada fortalecendo a auto-estima;

- se oferece assistência, consideração e informação permitindo ações educativas, controle de ansiedade e possibilita diminuir a vulnerabilidade a problemas emocionais;

- se fornece ajuda material e/ou econômica;

- se promove integração social, de forma a favorecer a pessoa a se sentir parte de uma rede ou sistema de apoio, com obrigações mútuas ou ajuda recíproca.

Desta forma, quanto mais suporte social um indivíduo obtém, mais apto estará para evitar situações de estresse ou desenvolver condições para enfrentá-las ou obstruí-las ${ }^{(4)}$.

Vários trabalhos têm ressaltado a importância da família como uma das mais relevantes fontes de apoio à mulher com câncer de mama, entretanto, quando a família decide apoiar esta mulher há necessidade de que todos os membros da família estejam bem $^{(1,5-7)}$.

As mudanças na rotina do dia a dia é um dos maiores fatores de estresse que o ser humano tem de lidar. Tais mudanças começam a ocorrer na vida da família de uma mulher com câncer de mama a partir das informações recebidas sobre o diagnóstico e das decisões a serem tomadas em relação ao tratamento ${ }^{(8)}$. A maneira como os membros ajustam-se afeta a maneira como a mulher se ajusta à nova situação.

Por considerarmos o parceiro sexual um importante elemento de suporte social para as mulheres mastectomizadas, este trabalho se propõe a avaliar e compreender como os parceiros se percebem na condição de elementos de suporte social para a reabilitação de suas parceiras e, para tanto, propomos como objetivo:

- identificar o tipo de suporte social, oferecido pelos parceiros sexuais de mulheres com câncer de mama, e como este apoio é percebido por eles.
Suporte social na reabilitação da mulher mastectomizada: o papel do parceiro sexual 


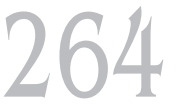

Rev Esc Enferm USP 2004; 38(3):262-9.

\section{MÉTODO}

Fizeram parte deste estudo nove parceiros de mulheres acometidas por câncer de mama que participam de um serviço especializado em reabilitação de mastectomizadas (o Rema) e fazem parte da clientela assistida pelo Núcleo de Ensino e Pesquisa na Reabilitação de Mastectomizadas - da Escola de Enfermagem Ribeirão Preto USP.

Para o recrutamento dos parceiros, as mulheres participantes do núcleo foram informadas sobre os objetivos da pesquisa durante as atividades assistenciais e foram solicitadas para convidarem seus parceiros a participarem do estudo. Após a confirmação da participação de cada um dos parceiros, na pesquisa foi explicado que as entrevistas seriam agendadas de acordo com a disponibilidade e local preferido de cada um e que seriam gravadas e posteriormente transcritas. Este trabalho foi submetido à análise do Comitê de Ética em Pesquisa da Escola de Enfermagem Ribeirão Preto USP, atendendo às Normas Regulamentares para o desenvolvimento de pesquisas com seres humanos de acordo com a Resolução 196/96 do Conselho Nacional de Saúde do Ministério da Saúde e assinado o termo de consentimento pós informado pelos sujeitos da pesquisa.

As entrevistas foram realizadas de forma privativa para o parceiro, ou seja, sem a presença direta da parceira sexual.

Os critérios de seleção dos parceiros participantes deste estudo se pautaram nas seguintes características das mulheres:

- casadas ou com parceiros fixos;

- residentes em Ribeirão Preto ou região;

- ter no máximo de 2 anos de pós-operada de câncer de mama.

Como instrumento de coleta de dados foi utilizado um roteiro de entrevista semiestruturada com tópicos previamente elaborados os quais direcionavam para o problema central.

As questões norteadoras do roteiro foram as seguintes: $\mathrm{O} \mathrm{Sr}$. pode contar-me como tem sido o dia a dia com sua mulher? Como era o relacionamento de vocês antes da cirurgia? Como tem sido o relacionamento agora? Como o Sr. se vê sendo uma pessoa de apoio para a sua mulher? Que tipo de coisas o senhor faz?

Para facilitar a organização na análise de dados, as entrevistas foram digitadas e armazenadas em computador.

A identificação de unidades temáticas após leituras e releituras exaustivas do conteúdo das entrevistas conforme descrita por $\operatorname{Bardin}^{(8)}$ foi o procedimento utilizado para a análise de dados.

Primeiramente procuramos encontrar unidades de significados nos depoimentos dos parceiros que os identificassem como elementos de apoio e, posteriormente, procuramos identificar suas dificuldades para oferecer este apoio.

\section{RESULTADOS E DISCUSSÃO}

O conteúdo das entrevistas dos nove parceiros desse estudo, após minuciosa leitura e releitura, permitiu-nos compreender como eles se reconhecem como elemento de apoio.

Diante dos relatos dos parceiros, identificamos que o suporte social oferecido pelos parceiros significou demonstração de afeto, compreensão da situação vivenciada por suas esposas mesmo que de forma silenciosa, incentivo às estratégias de autocuidado e colaboração nas atividades domésticas. Desta forma, o suporte foi percebido pois eles apoiaram suas parceiras demonstrando afeto, a medida que compreenderam as mudanças de comportamento de suas parceiras em conseqüência do câncer de mama.

A gente vai compreendendo, dando razão para ela. Ela era uma mulher muito diferente, alegre, agora ficou muito irritada com qualquer coisa.

É importante esta compreensão por parte dos parceiros no sentido de entender as atitudes das parceiras de forma a adequar-se às mudanças provocadas pela doença $\mathrm{e}$ tratamentos correspondentes ${ }^{(9)}$.

Os depoimentos dos parceiros evidenciam que eles compreendem, mesmo de forma silenciosa, as mudanças de atitude e alteração de emoções em sua parceira e procuram aceitar sem questionamentos. 
Acredito que todas as pessoas que passam por isso, os próprios medicamentos, além de mexer muito na intimidade, principalmente da mulher, quimioterapia, eu não entendo muito bem, mas eu acredito que deve alterar muito o metabolismo das pessoas, o sentido ou talvez a preocupação de que amanhã não esteja mais aqui, e realmente a pessoa se torna difícil.

O apoio, como suporte para o sucesso do processo de reabilitação, conforme interpretado pelos parceiros sexuais, corresponde ao que Cicchelli ${ }^{(10)}$ afirma, ou seja, quando se possibilita autonomia ao outro que necessita de apoio, este apreciará o apoio recebido, julgando-o necessário para a continuidade serena do trabalho de reabilitação. O acompanhamento de quem se pretende ofertar apoio, segundo o autor, deve ser discreto, tomar poucas iniciativas e intervir somente a pedido de quem necessita.

O afeto também foi expressado pelos parceiros como uma forma de compartilhar a situação vivenciada por elas quando oferecem carinho e atenção. Para eles, isso significou a mobilização de uma série de sentimentos, revelando o seu envolvimento junto à parceira.

\footnotetext{
O que eu faço para que amenize a dor dela(...)Carinho, este é o melhor remédio que eu posso dar para ela atualmente, e este carinho está incluído no trabalho, no dia-a-dia, nas coisas que eu faço dentro de casa, porque às vezes, acham que carinho é só quando se está passando a mão na cabeça, e carinho não é só isso, é um gesto, uma palavra, uma atitude.
}

Para os parceiros, este compartilhamento de uma situação vivenciada com uma doença séria como o câncer de mama, significou a mobilização de uma série de sentimentos, pois ao relatarem a experiência, fizeram-na com muita emoção, revelando o seu envolvimento junto à sua parceira. No momento em que uma pessoa está doente, a necessidade de carinho aumenta, e esta demonstração de afeto pode ter papel significativo no processo de $\operatorname{cura}^{(9)}$.

A proteção e a segurança oferecida pelos parceiros podem proporcionar alternativas para o enfrentamento dos problemas, estabelecer uma relação interpessoal positiva e um compartilhar afetivo de emoções, dúvidas e preocupações ${ }^{(11)}$.

Os parceiros estudados também se percebem como elementos de suporte social no processo de reabilitação quando incentivam o autocuidado de suas mulheres, demonstrando cuidado com o lar, oferecendo atenção no manuseio do dreno, nos curativos, estimulando a realização de exercícios e preocupando-se com a nova imagem corporal de suas parceiras.

\begin{abstract}
Quando foi para fazer os curativos me chamaram no hospital. Me orientaram direitinho e não teve problema, fiz tudo direitinho.
\end{abstract}

\section{Eu falo sempre para ela fazer o exercício que é preciso, não é.}

A concepção de tais conteúdos expressados pelos parceiros evidenciam que quando aquele que oferece ajuda e aquele que é ajudado estão juntos no investimento da situação vivenciada fazem convergir esforços mútuos para o enfrentamento dos problemas advindos daquela realidade ${ }^{(10)}$.

A demonstração de apoio dos parceiros também se estende às atividades do âmbito doméstico cujas atividades domésticas, quase que exclusivas das mulheres, passam a rever e reestruturar os papéis dos parceiros na rotina doméstica, acomodando estilos de vida ao regime do tratamento das esposas. $\mathrm{O}$ seguinte relato evidencia como o parceiro assume e sente a sobrecarga e intensidade do trabalho doméstico.

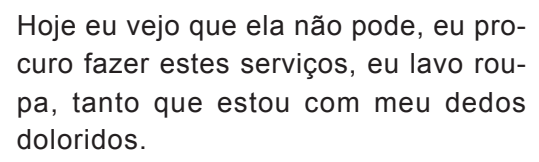

As mudanças na rotina do dia a dia é um dos maiores fatores de estresse com os quais o ser humano tem de lidar, e tais mudanças começam a ocorrer a partir das informações recebidas do diagnóstico e das decisões a serem tomadas em relação ao tratamento $^{(9)}$.

É importante o envolvimento dos parceiros, desde às mudanças da rotina doméstica até o processo de tomada de decisão em relação à mastectomia de sua parceira, podendo eles se tornarem um elemento central na condução de estratégias de prevenção primária em termos de potenciais emocionais ${ }^{(12)}$.
Suporte social na reabilitação da mulher mastectomizada: o papel do parceiro sexual 


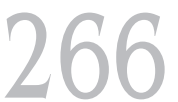

Rev Esc Enferm USP 2004; 38(3):262-9.
As dificuldades para oferecer suporte social às parceiras, foram mencionadas pelos parceiros como aquelas relacionadas à esfera sexual, aos canais de comunicação, à sensação de impotência e insegurança ao lidar com o diagnóstico e reorganizar as atividades domésticas. Ao falarem das dificuldades enfrentadas, explicam que o apoio oferecido por eles é uma obrigação, seja por questões de ordem moral, civil ou religiosa.

Tem que apoiar é lógico, sei disso, está escrito na Bíblia.

Proteção, não tem outro jeito.

Os parceiros revelam, portanto, que instituições como religião, casamento e sociedade funcionam como agentes de controle social.

A cultura dita normas em relação ao corpo; normas a que o indivíduo tenderá, à custa de castigos e recompensas, a se conformar, até o ponto de estes padrões de comportamento lhe apresentarem como tão naturais quanto o desenvolvimento dos seres vivos, a sucessão das estações ou o movimento do nascer e do pôr do sol ${ }^{(13)}$.

Dos depoimentos dos parceiros apre-endese que entre o desejo de estar junto e a necessidade de estar só envolve um processo de negociação que nem sempreé bem digerido por ambos.

O distanciamento do casal repercutindo diretamente no relacionamento sexual, também foi expresso pelos parceiros como dificuldades enfrentadas após a mastectomia de suas parceiras.

Ela perdeu o interesse, nunca vai para a cama junto, sempre tem uma desculpa de ficar até mais tarde e quando ela vai para cama eu já estou dormindo.

Afetou, entendeu(...)Depois da cirurgia o relacionamento sexual agravou mais um pouco.

Faz tempo, ela teve o problema e a gente foi deixando, mas foi só(...). A gente dorme junto, mas não tem essas coisas, relacionamento íntimo, não tem não.

Com efeito, esta situação pode constituir o agravamento de um processo de afastamento que prevalecia anteriormente no seio do casal.

Os parceiros do nosso estudo tiveram dificuldades de apoiarem as suas esposas após o aparecimento do câncer de mama, pois as dificuldades no relacionamento, existentes há anos, tornaram obstáculos a uma mudança com vistas ao apoio baseado em compreensão e diálogo.

Vários aspectos devem ser considerados em relação ao distanciamento do casal comprometendo o relacionamento sexual. Existe um tempo diferente para que o homem e a mulher compreendam o impacto emocional após a cirurgia ${ }^{(14)}$. Geralmente o homem sofre este impacto durante ou imediatamente após a cirurgia, enquanto que o impacto à mulher leva até um ano após a cirurgia. Isso poderá dificultar o entendimento do parceiro quanto aos aspectos adaptativos da mulher, aos efeitos do tratamento, pois sua esposa ainda está lidando com o trauma, provavelmente já resolvido por ele há meses.

As dificuldades de interação entre o casal também poderão estar relacionadas às diferentes versões ou ao melhor modo de lidar com a doença. $\mathrm{O}$ tempo precisa ser analisado no contexto das características específicas da etapa da doença a que este está associado, ou seja, o que está em jogo não é apenas a questão temporal, mas a própria complexidade da doença ${ }^{(15)}$.

Assim, pudemos perceber neste estudo, que os parceiros, de um modo geral, não estão compartilhando as suas incertezas provocadas pela doença de suas parceiras, seja pela diferença relacionada ao tempo do ajuste emocional, após a cirurgia, ou pelas dificuldades de expressarem seus sentimentos, e isso parece propiciar afastamento no relacionamento sexual.

Pudemos ainda verificar que o afastamento do casal, na esfera sexual, também pode relacionar-se à forma como ele encara a relação conjugal. Quando o parceiro entende que o corpo de sua parceira está para servilo, e se isso não acontece, cria-se logo um distanciamento.

\footnotetext{
Me deixa às vezes nervoso, também por causa do sexo, às vezes, sinto desejo mas ela(...)eu sinto que é por causa do problema, da doença, e eu vou relevando e ela me serve de má vontade.
}

A esse respeito, estudo lembra que o corpo, não como forma estática, mas como parte de uma sociedade, está preso a costumes e características próprias de cada 
cultura $^{(16)}$. O homem não nasce dotado de saberes, ele adquire à medida em que lhe é ensinado, pois não são seus instintos que lhe determinam suas ações como fazem os irracionais. Desta forma, o padrão cultural do comportamento sexual do parceiro ainda determina que o corpo da parceira está para servi-los e quando isso não acontece cria-se distanciamento entre eles.

Os dados ainda nos permitiu perceber que a falta de comunicação entre os casais é um problema que deve ser considerado na assistência de ambos. Essa falta de comunicação é percebida e revelada por eles especialmente quando sentem dúvidas e incertezas de como agir diante das mudanças de comportamento de suas mulheres as quais interferem na rotina do casal.

\begin{abstract}
Modificou, deita vira ao contrário...está pensando mais no problema dela e com certeza ela não ignora, não sei como é que fala, não tem aquela(...) está mais distante, então a gente reconhece em parte, mas fica pensando será que é por causa disso (câncer), por mim ou por alguma outra coisa entende? Então houve um afastamento, creio que deve ser normal devido essas coisas e tal.
\end{abstract}

A respeito do processo interativo entre casais, Noller ${ }^{(17)}$ procurou identificar a existência de diferenças de comunicações, independentes de situações de doenças, especialmente as não verbais entre casais e procurou ainda verificar se tais diferenças estavam relacionadas à qualidade do relacionamento marital.

Quanto às diferenças sexuais na comunicação não-verbal entre cônjuges, o autor revela que alguns casais podem estar se comunicando de outras formas que não sejam as verbais, como através de olhares, gestos, atitudes, onde um codifica e o outro decodifica as mensagens enviadas. Seus achados sugerem que homens e mulheres usam mensagens de formas diferentes em suas interações, o que provavelmente, pode dificultar o ajuste do casal. O estudo mostrou ainda que parceiros com baixo ajuste conjugal utilizam o olhar para monitorar o parceiro e deixá-lo consciente de suas reações ${ }^{(17)}$. Nas relações hostis, o olhar do parceiro funciona no sentido de adicionar intensidade ou confrontação de mensagens negativas. Por outro lado, em parceiros com bom ou elevado ajuste conjugal, as comuni- cações se faziam revelando que olhavam para o parceiro oposto, no sentido de demonstrar um desejo real de compreender o seu cônjuge.

Com essa visão, podemos perceber neste estudo que, de um modo geral, as mensagens enviadas, usadas para a comunicação entre os cônjuges, quando realizada de forma verbal, eram feitas sem reciprocidade, ou seja, quando um falava o outro não ouvia.

\section{Então agora tem outra, eu penso que ela também tem que colaborar com a gente, porque tem certas coisas que a gente fala e que ela tem que ouvir. Não é só o modo dela, tem que ser também o modo que a gente pensa que é.}

E mesmo quando o casal utilizou a comunicação não-verbal através de atitudes e gestos, não houve uma codificação entre eles.

Qualquer atitude minha de 5 minutos era o suficiente, e agora essas atitudes de 23 horas e 55 minutos não valem nada.

Cônjuges de elevado ajuste emocional também são mais semelhantes entre si nos seus padrões de olhar, particularmente no olhar enquanto ouvem o outro ${ }^{(17)}$. Tais achados sugerem uma certa qualidade de ajuste em seus padrões de olhar para cônjuges em casamentos felizes, o que não parece ter ocorrido nos cônjuges infelizes.

No presente estudo a interação do casal também revela que muitas vezes é prejudicada, especialmente, quando o parceiro percebe dificuldades em expressar sentimentos, criando neles a sensação de impotência e insegurança para lidar com as implicações do câncer de mama vivenciado pela parceira.

Isso aí me preocupa, fico olhando para ela, meu coração começa a machucar, não consigo fazer e falar nada, se minha esposa voltar do mesmo jeito (medo da recidiva), o que vou fazer na terra, difícil.

A inabilidade de alguns parceiros para oferecer apoio, pode estar relacionado à falta de habilidade para lidar com situações difíceis ${ }^{(2)}$. A dificuldade que os parceiros têm para proporcionar um diálogo franco e aberto é porque muitas vezes pode trazer à tona temas difíceis, como a morte e o medo da recorrência da doença, e, por essa razão, alguns parceiros evitam tais assuntos, pois assim fazendo, eles acreditam que se adaptarão mais facilmente à situação ${ }^{(18)}$. 
Se eu percebo também que ela não está muito boa, fico por aí como se não tivesse vendo nada.

Faz de conta que não está acontecendo nada, ponho ela no carro e vou passear.

As dificuldades dos parceiros para oferecer suporte também estão relacionadas às atividades domésticas. Essas atividades, acrescentadas às suas funções, nem sempre são consideradas como suas, alguns relatam que ajudam no trabalho doméstico, mas não as assumem como responsabilidades suas, geralmente eles escolhem aquilo que querem fazer.

Se eu tenho tempo eu arrumo a cozinha para ela de manhã cedo, porque eu levanto às 5 horas da manhã.

A respeito dos papéis sexuais na expressão de sentimentos, Simonton ${ }^{(8)}$ esclarece que, devido aos esteriótipos sociais impostos pela sociedade, os homens sentem mais dificuldades para exercer atividades tidas como femininas. Sentem também dificuldade de expressar medo, especialmente quando estão vivenciando a situação de câncer de mama da parceira.

O fato de um indivíduo ser do sexo masculino ou do sexo feminino não significa apenas que ele possui uma determinada conformação anatômica e fisiológica, significa também que ele possui um status social cujos limites, direitos e obrigações estão devidamente convencionados e em relação aos quais a comunidade mostra determinadas expectativas. Cozinhar ou dirigir uma empresa, caçar ou costurar, cuidar das crianças ou ler jornal são ilustrações destas expectativas, que cada sociedade define à sua maneira ${ }^{(13)}$.

Os depoimentos dos parceiros revelam que as tentativas de compreensão do patológico como fenômeno exclusivamente biológico e individual estão fadadas a um sucesso bastante relativo ${ }^{(13)}$. Isto porque a capacidade de pensar, exprimir e identificar as mensagens corporais presentes nos depoimentos dos parceiros estudados subordinaram-se a uma linguagem, cujo instrumento serviu para materializar a expressão dos significados atribuídos à condição de ser doente, ter um câncer de mama. A explicação que os parceiros dão é que a condição da esposa doente exige deles não somente o delineamento de proteções simbólicas, para proteger a esposa, mas também anunciam que muitas de suas atitudes se dirigem para a proteção de si próprios.

Assim, a demonstração de afeto, o reforço das estratégias de autocuidado, a ampliação de responsabilidade nos afazeres domésticos são algumas facetas de suas representações, da necessidade de oferecer apoio por entenderem a doença como um acontecimento eminentemente social.

Da mesma forma, as dificuldades reveladas pelos parceiros para o oferecimento de suporte social às esposas doentes como a falta de diálogo, sensação de impotência para o enfrentamento da situação, exercício da sexualidade representam o conteúdo e esforço que eles têm desenvolvido para lidar com as forças invisíveis que os ameaçam, forças estas que muitos deles demonstram um certo interesse em minimizar. Os parceiros sexuais, nos seus processos interpretativos relacionados ao oferecimento de suporte social às parceiras, conseguiram avaliar a qualidade do apoio dado, identificar um sistema de posições sociais assumidos nessa relação onde atribuíram direitos, deveres e obrigações e se definiram, ora como elementos de proteção, ora como elementos inseguros, confusos e que necessitavam também de apoio.

O depoimento dos parceiros estudados permitiu-nos apreender que a vida cotidiana deles se afigura com um continuum de tipificações que variam desde relações contínuas, freqüentes, intensas e às vezes distantes, que configuram um consciência de "nós", reconhecendo-se como pertencendo ao mesmo grupo, tendo coisas comuns, até relações vagas, fracas, indiretas.

O temor da doença para o parceiro, portanto, a razão desta ser socialmente vista como perigosa, está no fato de ser uma categoria de posição intermediária, ambiguamente situada entre a condição de vida e a condição de morte. Nesse sentido, ao vivenciarem essa situação os parceiros revelam que o processo de ajuda é fundamental. Neste sistema de comunicação, as emoções estão submetidas a um sistema de convenção que ditam a intensidade, a situação e a sua forma. 


\section{CONSIDERAÇÕES FINAIS}

O estudo, ao mostrar que os parceiros sexuais de mulheres com câncer de mama se percebem como importantes elementos de suporte social para suas esposas, identifica que a objetivação desse suporte é permeada por uma série de dificuldades que funcionam tanto para aproximar como para distanciar a relação de ambos.

Nesse sentido, tais resultados apontam para os profissionais da saúde que dirigem seus esforços para o trabalho de reabilitação de mulheres com câncer de mama, facetas inéditas do cuidado que necessitam de um olhar mais atento: o parceiro sexual para tornar-se um elemento de suporte social para sua parceira, necessita do olhar da pessoa a que ele atribui importância e sentido, ou seja, necessita de ajuda para rediscutir a sua identidade e papel social.

Fica evidente que para compreender como os parceiros sexuais, que ao mesmo tempo, apresentam dificuldades, mas apreciam e oferecem apoio, é necessário analisar a lógica das dificuldades encontradas por eles ou a lógica do apoio oferecido combinando as três dimensões: $o$ apoio esperado, o apoio recebido e a relação do parceiro com a doença da esposa.

Este trabalho expressa, portanto, um terreno fértil para pesquisas e demandas de melhoria do cuidado às mulheres com câncer de mama e seus parceiros.

\section{REFERÊNCIAS}

(1) Wolff LR. Rede de suporte social da mulher mastectomizada. [dissertação] Ribeirão Preto (SP): Escola de Enfermagem Ribeirão Preto/ USP; 1996.

(2) Feather BL, Wainstock JM. Perceptions post mastectomy patients. Part I. The relationships between social support and network providers. Cancer Nurs 1989; 12(5):293-300.

(3) Wortman CB. Social support and the cancer patient. Conceptual and methodologic issues. Cancer 1984; 53 (10 Suppl):2339-62.

(4) Fernandes AFC. Mulher com câncer de mama: estrutura familiar, cotidianidade e identidade. [dissertação] Fortaleza (CE): Universidade Federal do Ceará; 1992.

(5) Mamede MV. Reabilitação de mastectomizadas: um novo enfoque assistencial. [tese] Ribeirão Preto (SP): Escola de Enfermagem de Ribeirão Preto/USP; 1991.

(6) Clapis MJ. Qualidade de vida de mulheres com câncer de mama - uma perspectiva de gênero. [tese] Ribeirão Preto (SP): Escola de Enfermagem de Ribeirão Preto/USP; 1997.

(7) Almeida AM. Vivendo com a incerteza da doença: a experiência de mulheres com câncer de mama. [tese] Ribeirão Preto (SP): Escola de Enfermagem de Ribeirão Preto/USP; 1997.

(8) Bardin L. Análise de conteúdo. Lisboa: Edições $70 ; 1977$.

(9) Simonton MS. A família e a cura. São Paulo: Summus; 1990.
(10) Cicchelli V. Individualismo e formas de apoio: entre lógica incondicional e personalização da parceria intergeracional. In: Peixoto CE, Singly F, Cicchelli V. Família e individualização. Rio de Janeiro: FGV; 2000. p. 113-32.

(11) Silva RM, Mamede MV. Conviver com a mastectomia. Fortaleza: FCPC; 1997.

(12) Wellisch DK, Jamison KR, Pasnau RO. Psychosocial aspects of mastectomy II: the man's perspective. Am J Psychiatry 1978; 32(4): 561-71.

(13) Rodrigues JC. O tabu do corpo. Rio de Janeiro: Vozes; 1983.

(14) Murat MD, Cordiolli, AV. A paciente mastectomizada. Rev Méd ATM 1984; 11(1): $161-3$

(15) Gimenez MGG, Queiroz Q. As diferentes fases do enfrentamento durante o primeiro ano após a mastectomia. In: Gimenez MGG. A mulher e o câncer. São Paulo: Psy; 1997. p. 173-95.

(16) Silva RM, Queiroz TA, Santos ZMSA. Corpo saúde e sexualidade. In: Yolanda FS, Franco, MC. Uma abordagem cultural da enfermagem. Florianópolis: Papa Livro; 1996. p. 73-80.

(17) Noller P. Sex differences in nonverbal communication in the marital situation. New York: Pergamon Press; 1984. Nonverbal communication and marital interaction. p. 167-78.

(18) Lichtman RR, Taylor SE, Wood JV. Social support and marital adjustment after breast cancer. J Psychosoc Oncol 1987; 5(3):47-74.
Suporte social na reabilitação da mulher mastectomizada: o papel do parceiro sexual 